\title{
Epidemiological, Clinical and Therapeutic Aspects of Laryngeal Papillomatosis in Mali
}

\author{
Fatogoma Issa Kone $^{1, ~}{ }^{*}$, Kadidiatou Singare ${ }^{1}$, KadiatouTraore ${ }^{1}$, Oumou Coulibaly ${ }^{1}$, Naouma Cisse ${ }^{1}$, \\ Siaka Soumaoro ${ }^{1}$, Djibril Samake ${ }^{2}$, Neuilly Tafo ${ }^{3}$, Diarra Kassim ${ }^{1}$, Konate N'faly ${ }^{1}$, \\ Boubacary Guindo ${ }^{1}$, Timbo Samba Karim ${ }^{1}$, Keita Mohamed Amadou ${ }^{1}$ \\ ${ }^{1}$ Department of Surgery, University Hospital Gabriel Toure, Bamako, Mali \\ ${ }^{2}$ Reference Health Center V., Bamako, Mali \\ ${ }^{3}$ Reference Health Center II., Bamako, Mali
}

Email address:

konefatogomaissa@yahoo.fr. (F. I. Kone)

*Corresponding author

\section{To cite this article:}

Fatogoma Issa Kone, Kadidiatou Singare, KadiatouTraore, Oumou Coulibaly, Naouma Cisse, Siaka Soumaoro, Djibril Samake, Neuilly Tafo, Diarra Kassim, Konate N'faly, Boubacary Guindo, Timbo Samba Karim, Keita Mohamed Amadou. Epidemiological, Clinical and Therapeutic Aspects of Laryngeal Papillomatosis in Mali. International Journal of Otorhinolaryngology. Vıl. 6, No. 1, 2020 , pp. 1-5. doi: 10.11648/j.ijo.20200601.11

Received: November 22, 2019; Accepted: December 5, 2019; Published: January 31, 2020

\begin{abstract}
Objectives: To study the epidemiological and clinical aspects and to identify our therapeutic difficulties. Material and Methods: this is a quantitative retrospective study covering a 9-year period from January 2009 to March 2017. Patient on patients seen outpatient dyspnea and dysphonia or referred to the University Hospital of Gabriel Touré in Bamako. Results: The hospital prevalence was $0.05 \%$. The age group of 7 to 12 years represents $37.5 \%$ of cases. The average age of patients has increased from 11.71 years to 1 year to 36 years. The sex ratio was 1.5 . The disease spent 28 months at $28.1 \%$. The main signs found were dysphonia, dyspnea and touch, which were 90.6\%, 6.3\% and 3.1\% respectively. Laryngoscopy in suspension detected $68.8 \%$ of lesions in the glottic cleft. The subglottic stage in 4 cases, Susglottic in 6 cases. Peeling with the forceps has been performed in all our patients. Conclusion: laryngeal papillomatosis remains a problem in our context. Dysphonia and dyspnea are the main signs of discovery of this condition. Diagnostic delay due to ignorance by some practitioners and geographical distance. This delay in diagnosis is responsible for the aggravation of the symptoms that may justify the indication of a certain tracheotomy. Peeling with a forceps during direct laryngoscopy is the only therapeutic alternative in our context.
\end{abstract}

Keywords: Papillomatosis, Larynx, Peeling, Endoscopy

\section{Introduction}

Laryngeal papillomatosis is defined as a papillary and squamous type of benign tumoral proliferation developed in the larynx and generally observed in children [1]. Papillomatosis affects both sexes equally in children, but predominates in men from 30 years of age. It results from infection with a virus called papillomavirus (HPV), mainly subgroup 6 or $11[1,2]$. The latter are more oncogenic than subgroups 8/18 and 31/34. However, HPV 11 is more aggressive and is more carcinogenic than HPV 6. A dysphonia longer than three weeks is suggestive in children and / or trauma dyspnea that can disrupt the schooling of the young child [3]. The endoscopic appearance is suggestive and correlated with histology confirms the diagnosis [3]. Papillomatosis macroscopically presents as whitish, exophytic, veinous or even villous lesions [4]. Its pathogenesis is poorly known but viral participation is now proven [4]. It creates a vital risk because of its obstructive and degenerative potential. Its evolution is mainly marked by the recurrence of papilloma despite the iterative treatments often resulting in sequelae type of stenosis of the glottal plane. Dissemination of the oropharynx, trachea, bronchi or lungs and malignant transformation constitute a significant 
source of morbidity [5]. Association of previous studies by Ag Mohamed et al highlighted problems ethiopathogenic and therapeutic that recognizes the management of papillomatosis in our country [1]. These various problems have been a source of significant morbidity and remain relevant. That is:

1. The inaccessibility of techniques: laser, injection of acyclovir and interferon alpha.

2. The delay of care.

3. Recurrence, during postoperative follow-up and loss of sight of certain patients residing in areas with difficult access geographically or financially.

The objective was to study the epidemiological and clinical aspects and to identify our therapeutic difficulties.

\section{Material and Methods}

\subsection{Type of Study and Framework of the Study}

This is a descriptive, retrospective quantitative study covering a 9-year period from January 2009 to March 2017.

\subsection{Population Andplace of Study}

The study was conducted in the Department of Otorhinolaryngology and Head and Neck Surgery at the Gabriel Touré Teaching Hospital in Bamako, Mali. The study focused on patients seen outpatient dyspnea and dysphonia or referred to the ENT department of Gabriel Touré, university Hospital in Bamako.

\subsection{Inclusion Criteria}

We included patients of all ages and sexes who were admitted to consultation or referred to the ENT department who presented with clinical signs (dysphonia, dyspnea), whose suspension laryngoscopy or nasofibroscopy found suspicious lesions of laryngeal papillomatosis and confirmed by histology. The operative specimen was sent to the pathological examination that concluded papillomatosis

\subsection{Exclusion Criteria}

We excluded all patients who were unable to benefit from suspension laryngoscopy and nasofibroscopy. The coexistence of papillomatosis with other cancerous ENT lesions was excluded. In each patient we performed direct laryngoscopy with excision by peeling bunches of grapes.

\subsection{Variable}

The variables studied concerned socio-demographic status, clinical data, therapeutic data and postoperative follow-up. Postoperative follow-up was established over a period of one year with the patients concerned or their relatives by telephone correspondence based on the following clinical signs. Finally, each of the selected files benefited from a recount according to the questionnaire contained in our file.

\subsection{Statistical Analysis}

The data entry and processing was done using a computer with software: Microsoft Word, Microsoft EXCEL and SPSS 17.

\section{Results}

\subsection{Prevalence}

We collected 32 cases of laryngeal papillomatosis over a period of 9 years and accounted for $0.05 \%$ of ENT hospitalizations, an annual frequency of approximately 3.5 cases per year. The age group of 7 to 12 years accounted for $37.5 \%$ of cases. The average age of patients was 11.71 years; with extremes ranging from 1 year to 36 years. The sex ratio was 1.5 .

\subsection{Symptomatology}

The disease duration of more than 12 months was 28.1\%. The main signs found were dysphonia, dyspnea and cough, representing respectively $90.6 \%, 6.3 \%$ and $3.1 \%$. All our patients had dyspnea on admission; dyspnea was classified according to the three-stage classification of Chevalier Jackson. Stage 1 represented 62.5\%, Stage 2 represented 25\% and Stage 3 represented 12.5\%. All our patients presented a medical treatment before admission to corticosteroids in $84.4 \%$, bronchodilators and oxygen therapy in $15.6 \%$. In our study $15.65 \%$ that is 5 cases of children had their mothers carrying genital warts.

\subsection{Treatment and Follow-up}

Tracheotomy was urgently performed $31.2 \%$ of our patients against $68.8 \%$ non-tracheotomies. Laryngoscopy in suspension detected $68.8 \%$ of lesions in the glottic cleft. The subglottic stage in 4 cases, supraglottic in 6 cases. Peeling was performed in all our patients. The number of peeling sessions varied from one to nine sessions (Table 1). The interval between sessions varied from one month to twelve months (Table 2). We noted in $65.6 \%$ of the cases the absence of recurrence after the first peeling over a period of two years.

Table 1. The number of peeling sessions.

\begin{tabular}{lll}
\hline Number of peeling sessions & Effective & Percentage \\
\hline A session & 21 & 65,6 \\
Two sessions & 6 & 18,8 \\
Three sessions & 2 & 6,3 \\
Four sessions & 2 & 6,3 \\
Nine sessions & 1 & 3,1 \\
Total & 32 & 100 \\
\hline
\end{tabular}

Table 2. Time between peeling sessions.

\begin{tabular}{lll}
\hline Time between peeling sessions & Effective & Percentage \\
\hline A month & 1 & 3,1 \\
Two months & 2 & 6,3 \\
Three months & 2 & 6,3 \\
Four months & 3 & 9,4 \\
Six months & 2 & 6,3 \\
Twelve months & 1 & 3,1 \\
Total & 11 & 34,4 \\
\hline
\end{tabular}




\section{Discussion}

\subsection{Epidemiological Data}

We collected 32 cases of laryngeal papillomatosis over a period of 9 years, which is an annual frequency of about 3.5 cases per year with a prevalence of $0.05 \%$ of hospitalizations in ENT. Laryngeal papillomatosis appears to be a rare condition in developed countries with a real frequency that remains difficult to specify [7]. Christen et al noted that 0.2 to 0.5 cases / 100000 inhabitants in Denmark [8]. Timbo et al reported an annual frequency of 3, 8 cases / year and a hospital frequency of $0.05 \%$ [9]. This result is comparable to our study. Papillomatosis is classically seen in children [9-11] which is comparable to that of N'diaye et al [12]. Studies have reported two peaks in laryngeal papillomatosis [13]. A first peak around the age of 2-5 years and the second peak around the age of 20-30 [13]. In our study, the age group 6 to 12 years accounted for $37.5 \%$ of cases. Our sample consists of 19 male patients and 13 female patients, a sex ratio of 1.43 . This masculine predominance is a classic statement well shared by author Zour A [13]. We found a history of genital warts in some mothers (15.65\% or 5 cases) comparable to the Zour A series [13]. This series found a single case of a history of genital warts in the mother of a child. Unlike some series like that of Maliki [14] did not find a history of genital warts in mothers after consultation of their file. Condyloma in the mother seems to be a factor favoring the occurrence of papillomatosis in children. HPV 6 and 11 are shown to be the two most common types of HPV associated with condylomaacuminata. Children with laryngeal papillomatosis were infected from the mother during delivery [14].

\subsection{Clinical Data}

The duration of evolution is the most delayed. She was 10 months in the Azouk series and 1 to 5 years in the Ondzotto series "[15]". In our study the duration of evolution was 3 and 12 months. This delay seems to be long and challenges parents and practitioners. Dysphonia was the main circumstance of discovery in our study with $53,1 \%$ cases. This sign is often unnoticed and commonplace in children, progressing to a stage of laryngeal dyspnea or the condition is likened to asthma or laryngitis [10, 16]. Before any dysphonia it is necessary to perform a laryngoscopic examination. At first it is a patient with dysphonia and the association of dyspnea is related to the progressive obstruction of the laryngeal sector. The dyspnea dyspnea association illustrating the diagnostic delay was noted in $37.5 \%$. The lack of information, education and awareness of parents and health workers explains this aspect. It is reported that late diagnosis results in the occurrence of an inspiratory bradypnea with draft and cornea [13]. The advanced stage of dyspnea in twelve of our patients corroborates with some studies like that of Maliki [13]. He is the witness of a delayed diagnosis. Endoscopy under general anesthesia allows the assessment of lesions according to Maliki [14]. It shows tufts of raspberry-like, maturate, greyish-pink, cluster-like papilloma [12]. It begins on the floor of the ventricles, on the anterior commissure and on the anterior third of the vocal cord and can extend to the entire larynx, even the hypo pharynx and the bronchial trachea tree [14]. We noted that the frequent localization of papilloma at the glottic and glottic levels explains the presence of dysphonia in all our patients. The pediculated aspect of papilloma accounted for $65.5 \%$ of cases. Subglottic localization represented $18.8 \%$ as in the Maliki series where it was less representative [14]. Subglottic localization is dramatic because of the reduction of the size of the die at this level, appearing from the outset in the form of dyspnea. We did not have a topographic location of the trachea and bronchus, unlike those of Zour A [13], which found only one case of tracheal involvement. This location is a source of therapeutic morbidity. The histological study of papilloma is necessary, particularly in adolescents where a malignant transformation is to be feared [14]. We did not have a malignant transformation, unlike Zour A [13], who had a patient who had a malignant transformation at the end of his 3rd peeling session after 5 years of evolution which required a total laryngectomy whose consequences in the medium and long term were without particularity. We obtained an anatomopathological result in all cases; the results obtained all mean the keratinization at the level of the squamous epithelium with edema and lymphocytic infiltrate at the level of the conjunctivo-vascular axis. We performed tracheostomy in $31.2 \%$. Maliki performed the tracheotomy in $76 \%$ and Timbo in $47.4 \%$. The tracheotomy is a lifesaving prowess; it allows lifting the course of dyspnea and following the stage of healing. We performed them for therapeutic purposes in patients with severe dyspnea. This tracheostomy is known to be a factor compromising the prognosis of the disease in the long term. It promotes the spread of papillomatosis in the tracheobronchial tract [13]. In all our tracheotomized patients no case of dissemination was noted. Decannulation was obtained in all our patients as in other series [13].

\subsection{Treatment Data}

The treatment was symptomatic and palliative in all cases. The peeling was done in all cases with the forceps and under general anesthesia with extremes of one to nine sessions. Hemostasis was obtained after the application of xylocaine to naphazoline 5\%. Intubation is not always done despite the lack of tracheotomy and ventilation jet making the act acrobatic. Tracheotomy was performed in 10 cases (31.2\%). Iterative peeling of papilloma with laryngoscopic suspension was the only therapeutic option for all patients in our study and reported by many authors [9, 12, 14, 15]. On the other hand, tracheostomy has been a life-saving gesture for some patients admitted for severe laryngeal dyspnea, in this study this is due to the lack of knowledge of the pathology by many practitioners leading to late diagnosis by the ENT specialist. There are other treatments, namely: endoscopic $\mathrm{CO}_{2}$ laser vaporization is the most widely used method in the treatment of laryngeal papillomatosis [15]. The microdebrider has recently been proposed for the treatment of laryngeal 
papillomatosis [16, 17]. Among the drug alternatives, interferon alpha 2a, daily or weekly subcutaneous injection, has long been practiced [18]. The use of cidofovofir by the local route (intra-lesional injection) after surgical removal of papilloma is practiced [19, 20]. In these aggressive forms, several authors agree to associate with laser, immunotherapy or interferon [21]. The use of HPV 6 and HPV 11 vaccines has no effect at present on recurrent and aggressive forms [14]. In our context of deficient technical platform, no patient has benefited from this treatment; it was similarly reported by other African authors [9, 12, 14, 22]. Life-threatening is a function of the evolutionary form and obstructive status of the tracheostomy tube [13] Cases of death have been reported by Ondzotto however no death case was noted in our study. The malignant degeneration has been reported by some authors $[23,24]$ hence the interest of systematic histological examination in any case of recurrence. We have also noted cases of voice hoarseness in our patients who have undergone repetitive peeling at the forceps. It is reported that the functional prognosis is corollary to the frequency of peeling at the forceps [13]. Close monitoring and careful clinical examination make it possible to detect these cases of recurrence early in order to adapt an appropriate treatment. It will have the advantage of avoiding the iterative tracheotomies providing dissemination to the tracheobronchial tree.

\section{Conclusion}

Laryngeal papillomatosis remains a problem in our context. Dysphonia and dyspnea are the main signs of discovery of this condition. Diagnostic delay due to ignorance by some practitioners and geographical distance. This delay in diagnosis is responsible for the aggravation of the symptoms that may justify the indication of a certain tracheotomy. Added to this is the small number of ENT surgeons. it is about a pathology with a potential of recidivism requiring a perfect eplucahge in our context. Regular monitoring makes it possible to detect more recidivism and to perform rapid peeling. Peeling with a forceps during direct laryngoscopy is the only therapeutic alternative in our context.

\section{Conflicts of Interest}

All the authors do not have any possible conflicts of interest.

\section{References}

[1] Mohamed A AG, Timbo S K, Konipo-Togola F. La papillomatose laryngée: Réflexions à propos de 06 cas récents dans le service d'ORL-CCF de l'hôpital Gabriel touré Bamako (mali). Médecine d’Afrique Noire. 1996, 43: 12.

[2] Awad R, Shamil E, Aymat-Torrente A, Gibbins N, Harris S. Management of laryngeal papillomatosis using coblation: another option of surgical intervention. European Archives of Oto-Rhino-Laryngology. 2019. doi.org/10.1007/s00405-019-
05354-3.

[3] Fuchsmanec, Ayari - Khalfallalh S, Coulombeau B, Froechlich P. Papillomatose laryngée. Encycl Med Chir. Otorhino-laryngologie 2012, 20: 705-a-10.

[4] Saumet L, Damay A, Jerziorski E, Cartier C, Rouleau C, Margueritte G, et al. Papillomatose laryngée sévère évoluant vers un carcinome broncho-pulmonaire associé à HPV 11chez un enfant de 15ans: à propos d'un cas. Arch pediatr. 2011; 18: 754-7.

[5] Derkay CS, Wiatrak B. La papillomatoses laryngée de l'enfant. Recurrent respiratory papillomatosis a review. Laryngoscope. 2008; 118: 1236- 47. 241.

[6] Cook Jr, Hill Da, Humphrey Pa, Pfeifer Jd, El-MoftySk, squamous cell carcinoma arising in recurrent respiratory papilloatosis with pulmonary involvement: emmerging common pattern of clinical features and human papillomavirus serotype association. Mod Pathol. 2000; 13 (8): 914-8.

[7] K Pémissi E, Agbere Ab, Sossou K. papillomatose laryngée de l'enfant. Rev laryngol. 1995; 116: 335-338.

[8] CristenPh, Jorgen K, Grontred A. juvenile papillomatosis of the larynx, the country of funen, a 45 year follow-up from danemarkotolaryngol. 1984; 412: 3739.

[9] Timbo S. K, Konipo-Togola F, Mohamed Ag, Keita M A, Sacko H B, TraoreL. papillomatoselaryngée au mali. Bull soc patho exot. 2002; 95: 31-33.

[10] Diouf R, Ouaba, N'diaye I, Diop Em, Diop Ls, la papillomatose laryngée: à propos de 27 cas dakar med. 1989; 34: 102-106.

[11] Bauman Nm, Smith R J. recurrent respiratory papillomatosis pediatric clinic north am. 1996; 43: 1385-1401.

[12] N'diaye M, N' DiayeIc, I Tière, O Fa, Tall, Diallo Big, Diouf R, DioufEhm. Papillomatose laryngée de l'enfant. f r orl. 2008; 94: 379-382.

[13] Zour A., Raji A: papillomatose laryngée: aspects diagnostics thérapeutique et évolutifs [thèse]. Service d'orl et de chirurgie cervico-faciale CHU Mohamed Marrakech a propos de 20 cas faculté de médecine et de pharmacie Marrakech; 2011.

[14] O Maliki, H. Nouri, T. Ziad, Y. Rachid, L. Averdour, A. Raji. Papillomatose laryngée de l'enfant: aspect épidémiologique, thérapeutiques et évolutifs à propos de 21 cas journal de pédiatrie et de puériculture. 2012; 25: 237-241.

[15] Ondzotto G, Galiba J, Kouasi B, Ehoua F. La papillomatose laryngée: diagnostic précoce, à propos de 7 cas diagnostiques au chu de brazaville, congo. med tropicale. 2002; 62: 163-165.

[16] Silverberg $\mathrm{Mj}$, Thorsen $\mathrm{P}$, Lindeberg $\mathrm{H}$ et al condylome in pregnancy is strogly predictive of juvenile -onset recurrent respiratory papillomatosisobstetgynecol. 2003; 101: 645-652.

[17] Weys D Ou, Kashima Mk. tracheal involvement in laryngeal papillomatosis laryngoscope. 1983; 93: 45-48.

[18] Mesolella M, Motta G, Larguardia M, Galliv. papillomatosis of the larynx: treatement with $\mathrm{CO}_{2}$ laser. B E N T. 2006; 2: 51-54.

[19] Patel N, Rowe M, Turkel D. Treatement of recurrent respiratory papillomatosis in the children. annotalrhinol laryngol. 2003; 11: 9-10. 
[20] Pasquate K, Wiatrak B, Wooley A, Lewis L. microdebrideur versus $\mathrm{CO}_{2}$ laser removal of recurrent respiratory papillomatosis: a propective analysis laryngoscope; 2003; 113: 139-143.

[21] LoventholBg, Kashima Hk, Mounthp, Thurmond, Chapman S, Buckkleys et al. Long term reponsepapillomatose of recurrent respiratory papillomatosis to treatment with lymphoblastoid interferon. N Engl J Med. 1991; 325; 613-637.

[22] El Aatmani M, Steinnaetz A, Debry C, Leveque D, Koffel Jc, Beretz. a propos d'un cas de traitement de papillomatose laryngée récidivante par injection intra lésionnelle de cidofovir. J pharma clin. 2002; 21: 287-290.

[23] Traissac L, Devars F, Petit J, Portman D, Paraxanthros M, Benchaqroun $\mathrm{L}$ et al. Résultat du traitement de la papillomatose juvénile du larynx à propos de 158 cas. rev laryngeal. 1987. 108: 221-224.

[24] Toussaint B, Mayot D, Perrain C. transformation maligne de la papillomatose laryngée de type juvénile. Ann Otolaryngeal Chir Cervico Fac. 1993; 110: 285-290. 